\title{
Pyridyl-Cyclopentadiene $\operatorname{Re}(\mathrm{CO})_{2}{ }^{+}$Complexes as a Compact Core Systems for SPECT Ligand Development
}

\author{
Nathan C. Ackroyd ${ }^{\star}$ and John A. Katzenellenbogen ${ }^{\dagger}$ \\ † Department of Chemistry, University of Illinois, 600 South Mathews Avenue, Urbana Illinois, \\ 61801 \\ * Department of Chemical and Biological Sciences, Mount Royal University, 4825 Mount Royal \\ Gate SW, Calgary Alberta Canada T3E 6K6
}

\begin{abstract}
An $\eta^{1} \eta^{5}$-rhenium complex has been prepared, starting from a $\mathrm{CpRe}(\mathrm{CO})_{3}$ complex substituted with a pendant aromatic amine. This unique complex has potential application as a surrogate for a technetium-99m complex, a common radioisotope for biomedical imaging applications. Chelation occurred via photochemical decarbonylation of the rhenium, which opened a binding-site for the aromatic amine.
\end{abstract}

\section{Keywords}

Technetium 99-m; Radiopharmaceuticals; Imaging; Rhenium

\section{Introduction}

Because of its long half-life (6h) and wide-spread availability, ${ }^{99 \mathrm{~m}} \mathrm{Tc}$ is currently used for approximately $85 \%$ of all clinical radioisotopic imaging applications.1, 2 Examples of the use of technetium in imaging include simple complexes such as the myocardial imaging agent Sestamibi, ${ }^{\circledR} 3,4$ as well as technetium-containing complexes appended to biological molecules of interest, 5 often macromolecules. $6,7,8 \mathrm{~A}$ commonly used pendent complex is the organometallic cyclopentadienyl tricarbonyl technetium unit, $\mathrm{CpTc}(\mathrm{CO})_{3}$, because of its high stability 9 and the ease with which it can be prepared.10,11,12 The $\mathrm{CpTc}(\mathrm{CO})_{3}$ unit works well with high molecular weight biomolecules, whose physical and chemical properties dominate over the relatively small pendant complex. With smaller biological molecules and small molecule drugs, however, the polarity and steric size of the three carbonyl ligands have the potential to negatively affect pharmacokinetic properties. Burying the metal further within the ligand would reduce its accessibility to solvent and replace one of its CO groups, a change that is predicted to reduce its surface polarity by approximately one $\log$ unit.13 With this in goal in mind, it was decided to synthesize a model complex using rhenium in place of technetium, with an pyridylmethyl substituent added to the $\mathrm{Cp}$ core. The nitrogen of the pyridine should allow it to displace a $\mathrm{CO}$ under photochemical conditions and bind the metal with a second binding site, as shown in Figure 1.14

$\dagger$ jkatzene@uiuc.edu

nackroyd@mtroyal.ca. 


\section{Results}

To reduce exposure to radioactive isotopes, all synthetic steps were performed using rhenium instead of technetium.15 Rhenium has been widely used as a surrogate for technetium because rhenium analogs of technetium compounds can generally be prepared under similar conditions and their physical properties are similar. The synthesis of $\eta^{1} \eta^{5}$ pyridylmethylcyclopentadienyl rhenium(I) dicarbonyl $\mathrm{Py} C p(\mathrm{CO})_{2}$ involves two key steps: the attachment of the metal tricarbonyl to a cyclopentadienide, and the displacement of one carbonyl ligand and the concomitant cyclization to produce an $\eta^{1} \eta^{5}$ complex. Production of the pyridyl cyclopentadiene $\mathbf{3}$ proceeds in two steps from commercially available 2pyridylmethanol (1), as shown in Scheme 1. $\alpha$-Hydroxypicoline (1) was activated as the tosylate 2,16 which was displaced using $\mathrm{Cp}$ anion to form the mono-substituted cyclopentadiene $\mathbf{3}$. Cyclopentadiene $\mathbf{3}$ was isolated as a mixture of isomers, due to the propensity of cyclopentadienes to undergo 1,5-hydride shift, which in the case of substituted rings results in double bond regioisomers. No Diels-Alder dimerization of $\mathbf{3}$ was observed under standard isolation and characterization conditions at room temperature. Deprotonation of the cyclopentadiene $\mathbf{3}$ isomers formed one nucleophilic dienide, which coordinated to a rhenium tricarbonyl complex to form the piano-stool pyridylmethyl Cp complex 4.17 The essential pyridine to rhenium cyclization occurs via photo-irradiation under inert atmosphere to provide the desired rhenium dicarbonyl complex 5.14

\section{Discussion}

Several examples exist in the literature of transition-metals, including rhenium, with bidentate alkyl-amine substituted cyclopentadienide ligands.14,18,19,20 Examples of Cp ligands with aromatic amine substituents are far less common,21,22 and are not uniformly bidentate.23 To our knowledge, this is the first example of a pendant aromatic amine bound to rhenium. Our interest in such complexes is twofold: rhenium complexes serve as model systems for technetium in the development of imaging agents; 15 and there is a need to modify the in vivo stability and pharmacokinetic properties of certain metal complexes such that they make effective small-molecule imaging agents.

Comparison of the energy minimization space-filling models of the $\eta^{5}$-complex (Figure 2) and the $\eta^{1} \eta^{5}$-complex (Figure 3 ) illustrate the change in topology that arises from pyridine chelation. The original $\mathrm{CpRe}(\mathrm{CO})_{3}$ complex 4 (Figure 2) shows the classic "piano stool" structure, with the $\eta^{5}$-tricarbonyl metal system extending normal to the plane of the cyclopentadienyl ring on one side, with the pyridine substituent angled to occupy space on the other side of the Cp ring. By contrast, in the $\eta^{1} \eta^{5}$ - complex 5 (Figure 3), the pyridyl ring, in replacing one of the $\mathrm{CO}$ ligands, has rotated downward onto the other face of the $\mathrm{Cp}$ ring where it overall wraps itself much more around the metal center, making a more compact structure. We were surprised, however, to find that chelation did not have the effect on surface polarity predicted by calculations. Using an ethyl acetate/hexanes mixture showed no separation of the two complexes by thin layer chromatography. Instead, purification of the $\eta^{1} \eta^{5}$-complex was accomplished by precipitation from a mixture of both complexes. The addition of hexanes to a methylene chloride solution resulted in the selective precipitation of the $\eta^{1} \eta^{5}$-complex, suggesting that the surface polarity was increased, rather than decreased as expected. It appears that the loss of a polar CO ligand was more than compensated for by the introduction of formal charge on the pyridyl nitrogen.

\section{Conclusion}

We present here the synthesis of an $\eta^{1} \eta^{5}$-cyclopentadienide rhenium complex with an aromatic amine side-chain chelated to the metal center. Polarity increased slightly due to 
chelation by the aromatic amine, a change that may be beneficial for some imaging applications. The selective synthesis of mono-substituted $\mathrm{Cp}$ rings for use as tethered imaging agents may be challenging; thus, the use of an appropriately substituted alkylpyridyl methanol would allow for introduction of a tether. Chelation could then used, or not, depending on the requirements to adjust the polarity or steric contour of the system.

\section{Experimental Section}

\section{General Comments}

Synthetic operations were carried out under an atmosphere of nitrogen or argon, using standard Schlenk techniques, and flame-dried glassware was used. All reagents are commercially available from Aldrich, Strem or Fisher, and were used without further purification, unless otherwise stated. Solvents were purified using a Solvent Dispensing System fabricated by J. C. Meyer, based on a design published by Pangborn, et al.24

Reaction progress was monitored using analytical thin-layer chromatography (TLC) on Silica Gel $60 \mathrm{~F}_{254}$ plastic plates from EM Science. Visualization was achieved by either using UV light (254 nm), or phosphomolybdic acid indicator. Purification was done either by recrystallization, or by flash column chromatography using Woelm silica gel $(0.040$ $0.063 \mathrm{~mm}) .25$

${ }^{1} \mathrm{H}$ and ${ }^{13} \mathrm{C}$ NMR spectra were recorded on a U400 or U500 Varian FT-NMR spectrometer. Chemical Shifts $(\delta)$ are reported in parts per million downfield from tetramethylsilane or by reference to proton resonance of incomplete deuteration of NMR solvent. Both high and low resolution electron impact (EI) and chemical ionization (CI) mass spectra were obtained on a VG Instruments 70-VSE spectrometer.

\section{2-Pyridylmethyl toluene-4-sulfonate (2)}

To a stirred suspension of crushed $\mathrm{KOH}(4.702 \mathrm{~g}, 83.37 \mathrm{mmol})$ in dry tetrahydrofuran (100 $\mathrm{mL}$ ), was added 10 drops deionized water, and 2-pyridylcarbinol (1) $(1.725 \mathrm{~g}, 15.81 \mathrm{mmol})$ and p-toluene sulfonate $(2.973 \mathrm{~g}, 15.65 \mathrm{mmol})$. Stirring was continued 18 hours at RT. The white solid was filtered was washed with diethyl ether, and the mother liqueur was dried over $\mathrm{Na}_{2} \mathrm{SO}_{4}$. Solvent was removed to provide a red oil (4.128 g, 99\%). Product was taken on without need for further purification. ${ }^{1} \mathrm{H} \mathrm{NMR}\left(\mathrm{CDCl}_{3}\right) \delta 8.41$ (ddd, $1 \mathrm{H}, \mathrm{J}=4.88,4.39$, 0.98), 7.73 (AA'XX', 2H, J=8.30), 7.58 (dd, 1H J=7.81, 7.69), 7.29 (d, 1H, J=7.81), 7.24 (AA'XX', 2H, J=8.55), 7.12 (ddd, 1H, J=7.69, 4.80, 0.49), 5.05 (s, 2H), 2.32 (s, 3H). ${ }^{13} \mathrm{C}$ NMR $\left(100 \mathrm{MHz}, \mathrm{CDCl}_{3}\right) \delta 21.28,71.54,121.69,123.10,127.67,129.64,132.33,136.65$, 144.82, 148.99, 163.22. EI-MS m/z $264.0\left(\mathrm{M}^{+}\right)$. Anal. Calcd for $\mathrm{C}_{13} \mathrm{H}_{13} \mathrm{NO}_{3} \mathrm{~S} 264.068748$. Found: HREI-MS 264.069052.

\section{2-Cyclopenta-1,4-dienylmethyl-pyridine (3)}

To a solution of $2.0 \mathrm{M}$ sodium cyclopentadienide $(150 \mathrm{~mL}, 300 \mathrm{mmol})$ was added a solution of 2-pyridylmethyl toluene-4-sulfonate (2) $(4.090 \mathrm{~g}, 15.53 \mathrm{mmol})$ at $0{ }^{\circ} \mathrm{C}$ in tetrahydrofuran $(100 \mathrm{~mL})$. Stirring was continued $90 \mathrm{~min}$. The solution was then quenched with $5 \mathrm{~mL} 6 \mathrm{~N}$ $\mathrm{HCl}$, neutralized with $\mathrm{NaHCO}_{3}$ and filtered through celite. The solvent was removed, and the residue was re-dissolved in ethyl acetate. The organic phase was washed with saturated $\mathrm{NaCl}$. The organic phase was filtered through celite and dried over $\mathrm{Na}_{2} \mathrm{SO}_{4}$. Solvent was removed to provide a brown oil which was was purified to a mixture of isomers by column chromatography over triethylamine-treated silica gel, eluted with 50\% ethyl acetate/hexanes (brown oil, $1.435 \mathrm{~g}, 59 \%) .{ }^{1} \mathrm{H}$ NMR $\left(\mathrm{CDCl}_{3}\right) \delta 8.52(\mathrm{~m}, 0.99 \mathrm{H}), 7.56(\mathrm{~m}, 1.07 \mathrm{H}), 7.14(\mathrm{~m}$, $1.07 \mathrm{H}), 7.09(\mathrm{~m}, 1.08 \mathrm{H}), 6.41(\mathrm{~m}, 1.75 \mathrm{H}), 6.24(\mathrm{~m}, 1 \mathrm{H}), 6.07(\mathrm{~m}, 0.63 \mathrm{H}), 3.90(\mathrm{~m}, 2.2 \mathrm{H})$, $2.97(\mathrm{~m}, 1.31 \mathrm{H}), 2.89(\mathrm{~m}, 1.18 \mathrm{H}) .{ }^{13} \mathrm{C} \mathrm{NMR}\left(100 \mathrm{MHz}, \mathrm{CDCl}_{3}\right) \delta 38.98,39.90,41.28$, 
$43.15,121.07,122.86,122.90,128.19,128.57,131.69,132.25,134.07,134.27,136.33$, 136.39, 144.06, 146.31, 149.17, 149.21, 160.14, 160.60. EI-MS m/z 157.1 ( $\left.\mathrm{M}^{+}\right)$. Anal. Calcd for $\mathrm{C}_{11} \mathrm{H}_{11} \mathrm{~N}$ 156.081324. Found: HREI-MS 156.081071.

\section{$\eta^{5}$-Cyclopentadienylmethylpyridinyl rhenium tricarbonyl (4)}

To a solution of cyclopentadienyl methylpyridine (3) $(0.222 \mathrm{~g}, 1.41 \mathrm{mmol})$ at $-78{ }^{\circ} \mathrm{C}$ in tetrahydrofuran $(10 \mathrm{~mL})$ was added $2.0 \mathrm{M} \mathrm{n}-\mathrm{BuLi}(1.4 \mathrm{~mL}, 2.8 \mathrm{mmol})$. Solution was stirred $5 \mathrm{~min}$. A solution of $\left[\operatorname{ReBr}(\mathrm{THF})(\mathrm{CO})_{3}\right]_{2}(0.603 \mathrm{~g} 0.71 \mathrm{mmol})$ in tetrahydrofuran $(10 \mathrm{~mL})$ was cannulated into solution (15) and stirring continued $20 \mathrm{~min}$, followed by quench with 3 $\mathrm{mL}$ methanol, $2 \mathrm{~mL} 1 \mathrm{~N} \mathrm{HCl}$. Organic phase was extracted with methylene chloride. Organic extracts were washed with saturated $\mathrm{NaCl}$ and dried over $\mathrm{Na}_{2} \mathrm{SO}_{4}$. Solvent was removed to provide a brown oil which was purified by column chromatography over triethylamine treated silica gel, eluted with 50\% ethyl acetate/hexanes (brown oil, $0.171 \mathrm{~g}$, 28\%). ${ }^{1} \mathrm{H}$ NMR $\left(\mathrm{CDCl}_{3}\right) \delta 8.53$ (dd, $\left.1 \mathrm{H}, \mathrm{J}=4.88,0.90\right), 7.63$ (ddd, $1 \mathrm{H}, \mathrm{J}=7.81,7.57,1.79$ ), $7.18(\mathrm{~d}, 1 \mathrm{H}, \mathrm{J}=7.81), 7.15$ (dd, 1H, J=7.57, 0.98), 5.37 (t, 2H, J=2.20), 5.21 (t, 2H, J=2.20), $3.82(\mathrm{~s}, 3 \mathrm{H}) .{ }^{13} \mathrm{C} \mathrm{NMR}\left(100 \mathrm{MHz}, \mathrm{CDCl}_{3}\right) \delta 36.77,83.47,84.73,107.18,121.90,122.75$, 136.85, 149.31, 158.97, 194.19. CI-MS $m / z$ 428.0 $\left(\mathrm{M}^{+}+1\right)$. Anal. Calcd for $\mathrm{C}_{14} \mathrm{H}_{11} \mathrm{NO}_{3} \mathrm{Re}$ 428.029658. Found: HRCI-MS 428.02965.

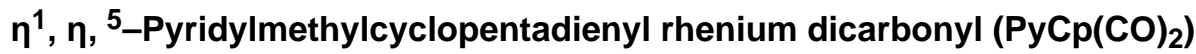

A solution of cyclopentadienyl rhenium (4) $(0.171 \mathrm{~g} 0.40 \mathrm{mmol})$ in dry tetrahydrofuran (10 $\mathrm{mL}$ ) in a quartz Schlenk tube under a nitrogen atmosphere was irradiated in a Rayonet apparatus under a nitrogen atmosphere with $300 \mathrm{~nm}$ low pressure $\mathrm{Hg}$ lamps for $90 \mathrm{~min}$. Solvent was removed to provide a red-brown solid which was purified by precipitation from methylene chloride using hexanes (red solid, $0.068 \mathrm{~g}, 42 \%) .{ }^{1} \mathrm{H} \mathrm{NMR}\left(\mathrm{CDCl}_{3}\right) \delta 8.94$ (dd, $1 \mathrm{H}, \mathrm{J}=4.89,1.52$ ), 7.39 (ddd, 1H, J=7.81, 7.57, 1.54), 6.80 (dd, 1H, J=5.13, 0.73), 6.78 (dd, $1 \mathrm{H}, \mathrm{J}=4.88,0.73), 5.47(\mathrm{t}, 2 \mathrm{H}, \mathrm{J}=2.08), 5.07(\mathrm{t}, 2 \mathrm{H}, \mathrm{J}=2.08), 3.75(\mathrm{~s}, 3 \mathrm{H}) .{ }^{13} \mathrm{C}$ NMR $(100$ $\left.\mathrm{MHz}, \mathrm{CDCl}_{3}\right) \delta 35.75,77.19,80.20,122.89,123.45,134.78,159.68,176.23,204.69$. FABMS $m / z 399.1\left(\mathrm{M}^{+}\right)$. Anal. Calcd for $\mathrm{C}_{13} \mathrm{H}_{10} \mathrm{NO}_{2} \mathrm{Re}$ 397.02415. Found: HRFAB-MS 397.0240 .

\section{Acknowledgments}

We thank the United States Army Medical Research and Materiel Command Breast Cancer Research Program DAMD-17-03-1-0681 and the National Institute of Health PHS 5R01 CA025836 for funding.

\section{References}

1. Mease RC, Lambert C. Newer Methods of Labeling Diagnostic Agents with Tc-99m. Semin Nucl Med. 2001; 31:278-85. [PubMed: 11710770]

2. Eckelman WC. Unparalleled Contribution of Technetium-99m to Medicine Over 5 Decades. JACC J Am Coll Cardiol Img. 2009; 2:364.

3. Cuocolo A, Acampa W, Imbriaco M, De Luca N, Iovino GL, Salvatore M. The Many Ways to Myocardial Perfusion Imaging. Q J Nucl Med Mol Imaging. 2005; 49:4-18. [PubMed: 15724132]

4. Okada RD, Glover D, Gaffney T, Williams S. Myocardial Kinetics of Technetium-99m-Hexakis-2Methoxy-2-Methylpropyl-Isonitrile. Circulation. 1988; 77:491-498. [PubMed: 3338137]

5. Kunstler J, Veerendra B, Figueroa SD, Sieckman GL, Rold TL, Hoffman TJ, Smith CJ, Pietzsch H. Organometallic 99mTc(III) '4 + 1' Bombesin(7-14) Conjugates: Synthesis, Radiolabeling, and in vitro/in Vivo Studies. Bioconjugate Chem. 2007; 18:1651-1661.

6. Svensson W, Glass D, Bradley D, Peters A. Measurement of Lymphatic Function with Technetium-99m-Labelled Polyclonal Immunoglobulin. Eur J Nucl Med Mol Imaging. 1999; 26:504-510. 
7. Thakur M, DeFulvio J, Tong J, John E, McDevitt M, Damjanov I. Evaluation of Biological Response Modifiers in the Enhancement of Tumor Uptake of Technetium-99m Labeled Macromolecules. A Preliminary Report. J Immunol Methods. 1992; 152:209-216. [PubMed: 1500731]

8. Zanelli G, Ellison D, Barrowcliffe M. The Preparation of Kits for Labelling Macromolecules of Biological Interest with Technetium-99m. Nucl Med Commun. 1987; 8:199. [PubMed: 2446223]

9. Aebischer N, Schibli R, Alberto R, Merbach AE. Complete Carbonylation of Fac[Tc(H2O)3(CO)3]+ Under CO Pressure in Aqueous Media: A Single Sample Story! Angew Chem Int Ed. 2000; 39:254-256.

10. Alberto, R.; Schibli, R.; Egli, A. Wo Patent. 9848848. 1998.

11. Wald J, Alberto R, Ortner K, Candreia L. Aqueous One-Pot Synthesis of Derivatized Cyclopentadienyl-Tricarbonyl Complexes of $99 \mathrm{mTc}$ with an in Situ CO Source: Application to a Serotonergic Receptor Ligand. Angew Chem Int Ed. 2001; 40:3062-3066.

12. Alberto R, Ortner K, Wheatley N, Schibli R, Schubiger AP. Synthesis and Properties of Boranocarbonate: A Convenient in Situ CO Source for the Aqueous Preparation of [99mTc(OH2)3(CO)3]+ J Am Chem Soc. 2001; 123:3135-3136. [PubMed: 11457025]

13. Calculations done using the Sybyl Program from Tripos.

14. Wang T, Lai C, Hwu C, Wen Y. Half-Sandwich Aminorhenium Complexes: Preparation and Regioselective N-Versus Re-Alkylations. Organometallics. 1997; 16:1218-1223.

15. Hoepping A, Brust P, Berger R, Leibnitz P, Spies H, Machill S, Scheller D, Johannsen B. Novel Rhenium Complexes Derived from [Alpha]-Tropanol as Potential Ligands for the Dopamine Transporter. Bioorg Med Chem. 1998; 6:1663-1672. [PubMed: 9838998]

16. Bradshaw JS, Huszthy P, McDaniel CW, Zhu CY, Dalley NK, Izatt RM, Lifson S. Enantiomeric Recognition of Organic Ammonium Salts by Chiral Dialkyl-, Dialkenyl-, and TetramethylSubstituted Pyridino-18-Crown-6 and Tetramethyl-Substituted Bispyridino-18-Crown-6 Ligands: Comparison of Temperature-Dependent Proton NMR and Empirical Force Field Techniques. J Org Chem. 1990; 55:3129-3137.

17. Mull ES, Sattigeri VJ, Rodriguez AL, Katzenellenbogen JA. Aryl Cyclopentadienyl Tricarbonyl Rhenium Complexes: Novel Ligands for the Estrogen Receptor with Potential use as Estrogen Radiopharmaceuticals. Bioorg Med Chem. 2002; 10:1381-1398. [PubMed: 11886802]

18. Okuda J. Bifunctional Cyclopentadienyl Ligands in Organotransition Metal Chemistry. Comments Inorg Chem. 1994; 16:185-205.

19. Jutzi P, Siemeling U. Cyclopentadienyl Compounds with Nitrogen Donors in the Side-Chain. J Organomet Chem. 1995; 500:175-185.

20. Wang TF, Hwu CC, Wen YS. Aminorhenium Carbon Dioxide Complexes: Formal Oxidation of a Carbon Monoxide Ligand with Peroxy-Acids Or bromine/hydroxide. J Organomet Chem. 2004; 689:411-418.

21. Enders M, Rudolph R, Pritzkow H. 8-Quinolylcyclopentadienyl, a Ligand with a Tailored Fit for Chelate Complexes. Chem Ber. 1996; 129:459-464.

22. Krut'ko D, Borzov M, Liao L, Nie W, Churakov A, Howard J, Lemenovskii D. 1Methylimidazol-2-Yl-Functionalized Cyclopentadienyl Titanium and Zirconium Complexes. Crystal Structure of [ $75: 1-\mathrm{C} 5 \mathrm{H} 4 \mathrm{CPh} 2 \mathrm{CH} 2-(1-\mathrm{MeC} 3 \mathrm{H} 2 \mathrm{~N} 2)]$ TiCl3. Russ Chem Bull. 2006; 55:1574.

23. Siemeling U, Vorfeld U, Neumann B, Stammler HG. Pyridyl-Functionalised Cyclopentadienyl Ligands: Building Blocks for Oligonuclear Organometallic Assemblies. Chem Ber. 1995; 128

24. Pangborn AB, Giardello MA, Grubbs RH, Rosen RK, Timmers FJ. Safe and Convenient Procedure for Solvent Purification. Organometallics. 1996; 15:1518-1520.

25. Still WC, Kahn M, Mitra A. Rapid Chromatographic Technique for Preparative Separations with Moderate Resolution. J Org Chem. 1978; 43:2923-2925. 

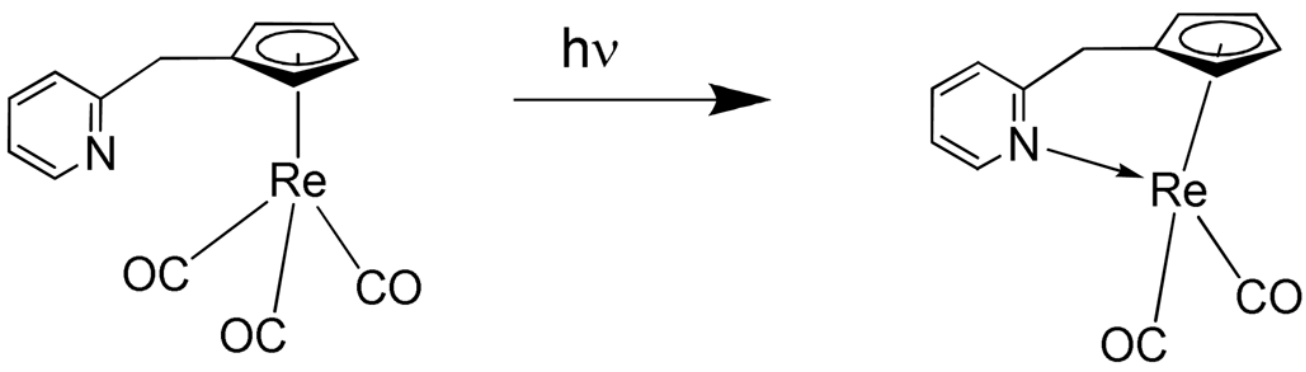

$\operatorname{PyCp}(\mathrm{CO})_{2}$

Figure 1.

Photochemical Cyclization 


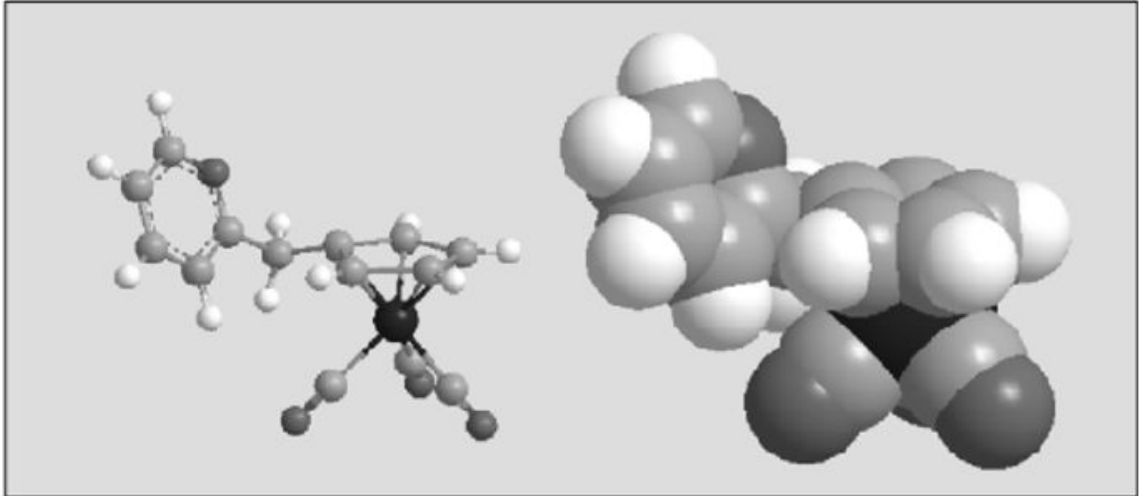

Figure 2.

Space-filling Model of $\eta^{5}$-Complex 


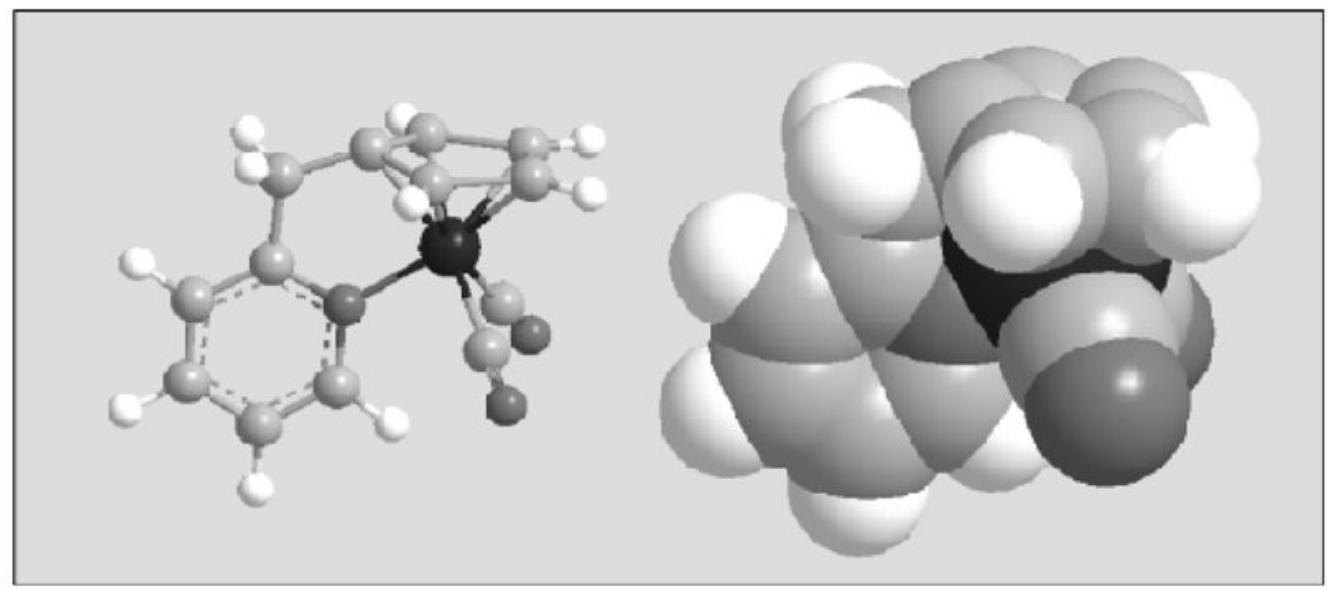

Figure 3 .

Space-filling Model of $\eta^{1} \eta^{5}$-Complex 


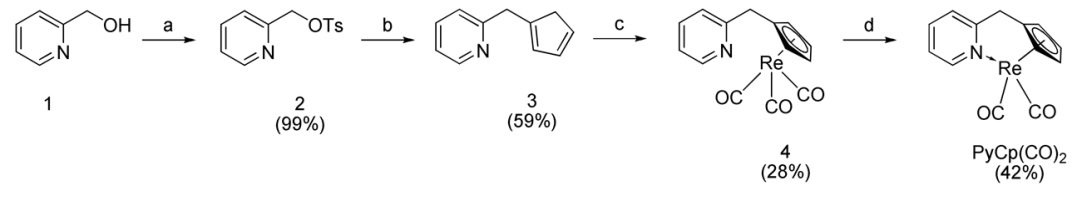

(a) TsCl, KOH, THF, RT, overnight. (b) $\mathrm{NaCp}, \mathrm{THF},-78^{\circ} \mathrm{C}$. (c) n-BuLi, $\left[\mathrm{ReBr}(\mathrm{THF})_{2}(\mathrm{CO})_{3}\right]_{2}, \mathrm{RT}, 20$ min. (d) $\mathrm{hn}, 300 \mathrm{~nm} .90 \mathrm{~min}$

Scheme 1.

Synthesis of Pyridyl-Cyclopentadienyl Core. 